\title{
POPULATION CONTROL IN PUERTO RICO: THE FORMAL AND INFORMAL FRAMEWORK*
}

\author{
KuRT W. BACK† \\ REuben HiLlf \\ J. MAYONE STYcos**
}

In the last two decades, Puerto Rico has become a model of the progress possible to underdeveloped countries. By any indices, its economic and social changes have been astounding. Rehabilitation of agriculture; creation of industry; exploitation of natural resources and of scenery for tourist trade; extension of social welfare, health, and educational services; and ingenious attempts at constitutional innovations have made the Puerto Rican story an example of possible achievement for countries in similar conditions.

In common with other modernizing countries, Puerto Rico has experienced a remarkable population increase. ${ }^{1}$ The population has doubled between 1910 and I950, and Puerto Rico is now a country with one of the highest population densities in the world, twelve times as high as that of the continental United States, and

- The writers of this article jointly directed the Family in Puerto Rico project and authored Tite Famaly and Population Control; A Puerto Rican Experiment in Social Chunge (1959), upon which much of this article is based and from which all data not ascribed to other sources have been drawn.

† B.S. 1940, New York University; M.A. 1941, University of California at Los Angeles; Ph.D. 1949, Massachusetts Institute of Technology. Associate Professor of Sociology and Psychiatry, Duke University. Author, [with Reuben Hill \& J. Mayone Stycos] The Family and Population Control; A Puzrto Rucan Experiment in Social Change (r959); [with J. Mayone Stycos] The Survey Under Unusual Conprtions (I959); [with L. Festinger \& S. Schachter] Social Pressures in Informal Groups (1950). Contributor to periodicals of articles on field experiments, communication and influence, and family planning.

† B.S. 1935, Utah State University; Ph.M. 1936, Ph.D. 1938, University of Wisconsin. Director, Minnesota Family Research Center, and Professor of Sociology, University of Minnesota. Author, [with J. Mayone Stycos \& Kurt W. Back] The Family and Population Control; A Puerto Rican Experiment in Social Change (I959); Sociology of Marriage and Family Behavior (1958); [with Howard Becker et al.] Family, Marriage, and Parenthood (2d ed. 1955); [with J. Joel Moss \& Claudine G. Wirths] Eddyville's Families (1953); [with Evelyn M. Duvall] When You MArry (rev. ed. 1953); [with W. W. Waller] The Family: A Dynamic Interpretation (r95I); Families Under Stress (r949); [with Howard Becker et al.] Marriage AND the Fanily (r942); and research monographs on family sociology.

** A.B. I947, Princeton University; Ph.D. 1954, Columbia University. Associate Professor of Sociology, Cornell University. Author, [with Reuben Hill \& Kurt W. Back] The Family and Population Control; A Puerto Rican Experiment in Sociaz Change (r959); [with Kurt W. Back] The Survey Under Unusual Conditions (i959); Family and Fertility in Puerto Rico (i955). Contributor to periodicals of articles on demography, fertility control, and research methods.

1 The Puerto Rican vital statistics are taken from Puerto Rico Department of Health, Monthly Vital Statistics Reports. 
surpassing the other Caribbean islands by more than two-thirds. The reason for this is a rapid decline in the mortality rate that was not accompanied by decline in the fertility rate. The death rate has dropped from about twenty per thousand as recently as thirty years ago, to 6.8 per thousand in 1959 , a rate that compares favorably with the most advanced western countries. ${ }^{2}$ The main reason for this is the effectiveness of recent advances in public health on the island. For instance, there have been no deaths from malaria recorded in the three years 1957, 1958, and 1959; previously, malaria was a major cause of death. Two other diseases that are important causes of death in tropical countries have similarly declined: intestinal diseases, because of the improvement in the water supply; and tuberculosis, because of the development of new drugs. Mortality attributable to these causes has declined by one-third even within the last decade. On the other hand, the birth rate has stayed rather steadily around forty per thousand from I9ro-1950 and has only started to drop since 1950 .

The population increase has produced serious problems. Puerto Rico has been more fortunate than other countries in similar conditions, in that it enjoys unrestricted migration to the continental United States. The large-scale migration to the major continental cities has alleviated the population problem in Puerto Rico itself, but it has also given the population problem widespread attention. Migration is only a partial solution, at best, and never has absorbed the total natural increase in population. The problems of Puerto Rican minorities in New York, Philadelphia, Chicago, and other cities, too, have shown the dangers of relying on large-scale migration to urban centers. In the long run, only a decline in the birth rate can achieve demographic equilibrium.

The question posed by the unequal decline in birth and death rates is not new. It was experienced in western Europe at the beginning of the industrial revolution and was followed, after about seventy years, by a corresponding decline in birth rate. Thus, we might expect that after a similar lapse of time, the countries that are now starting on the path to urbanization and industrialization will reach, again, a tolerable equilibrium. But while the conditions during the last century were quite favorable to the sudden spurt of population, principally because of the opening of new areas to settlement, the question is somewhat more urgent now. There is no frontier to move to, and within the country, the additional population threatens to nullify hard-won economic and social gains. Technical, economic, and social reforms do not have to be slowly created today, as during the last centuries in the West, but can be speedily adopted; similarly, control of fertility needs an accelerated pace to keep step with the other changes occurring in the country.

As it has with other social problems, Puerto Rico has confronted the question of fertility control early and has tried to deal with it. A recent small but consistent drop in birth rates has signified the possibility of success in this effort, and this

\footnotetext{
'By comparison, the United States death rate was 9.4 in I959. Nat'l Office of Vital Statistics, U.S. Dep't of Health, Education, and Welfare, Monthly Vital Statistics Report, April Ig6o, p. 5.
} 
experience may afford valuable insights into the population problems of many other modernizing countries. The peculiar emotions that are engendered by the question of birth control make Puerto Rico an especially apt place for the study of possible developments. Excessive population increase that may threaten the adequacy of resources and public services is a subject for public policy and has increasingly been recognized as a legitimate concern of public health. More than most other topics, however, it affects personal feelings and intimate relationships that are considered private matters. In all phases of Puerto Rican development, there has been great concern about assuring local participation and individual and group development as necessary conditions for any successful policy. This is owing partly to the commitment of the administration to consider personal development of the individual as the goal beyond economic advances, and partly to the general ethos of dignity that has been noted by many observers of the Puerto Rican scene. Thus, Puerto Rico lends itself well to the discussion of a topic that is so important for the community and deep-rooted in individual concerns.

Puerto Rico's concern with its population problem, in conjunction with its respect for the individual and belief in scientific planning, has led to a series of investigations of the general beliefs, attitudes, and practices surrounding birth control. This has provided extensive information about family planning in Puerto Rico and has made it possible to put the question into a more general perspective. Before turning to a discussion of Puerto Rican conditions, however, an outline of a general logical scheme under which social changes of this kind can profitably be considered may be illuminating.

Propositions concerning possible acts can be considered from two points of view: whether the statement is true or false, and, accordingly, whether the act is possible or not; and whether the act is right or wrong, and, accordingly, whether the act is forbidden or allowed. The former comprises the realm of alethic modal logic; the latter, of deontic modal logic. These types are extensions of two-value formal logic and are useful for the explication of such concepts as possibility, necessity, obligation, and permission. No formal exposition of these systems will be given here, but they will be developed as far as is necessary for a classification of activities for the purpose of this discussion. ${ }^{3}$

Modal logics are created by the addition of logical constants to the familiar set of constants: negation, disjunction, conjunction, implication, and equivalence. For alethic modal logic, the constants refer to necessity and possibility and operate on single propositions, as negation does. Thus, we can say of a given proposition that it is possible or that it is not necessary. We shall restrict the system and exclude combinations of possibility and necessity, avoiding involved expressions such as: "It is necessary that it is possible that...." With this restriction, a proposition can

This scheme is based directly on the work of Alan R. Anderson. Cf. Alan R. Anderson, Tris Formar Analysis of Normative Systexss (1956); Anderson, The Logic of Norms, in I Logic AnALYsB 84 (1958). His work is, in turn, a development of treatments by von Wright and Prior. The exposition of alethic and deontic modal logic follows closely Anderson. 
appear in six forms of alethic modality: it can be asserted or denied, it can be possible or not possible, it can be necessary or not necessary. These six modalities can be arranged in order of truth value, starting with assertion and ending with denial, the two modalities of ordinary two-value logic. As an example, let us display the proposition "people use birth control" in all modalities, arranged in order:

x. People use birth control.

2. It is necessary that people use birth control.

3. It is possible that people use birth control.

4. It is not necessary that people use birth control.

5. It is not possible that people use birth control.

6. People do not use birth control.

Deontic modal logic is created by the addition of the two constants of obligation and permission. This leads to four modalities, assertion and negation having no place along a normative continuum. Using the same example, they are arranged as follows:

r. It is obligatory that people use birth control.

2. It is permitted that people use birth control.

3. It is not obligatory that people use birth control.

4. It is not permitted that people use birth control.

It can be seen that the systems are very similar in their structure. In fact, under certain assumptions, the deontic system can be reduced to the alethic system. This is done by substituting for the form " $x$ is obligatory" the implication, "if $x$ is not done there is a sanction," and similarly for the other forms. This assumed equivalence between norms and sanctions corresponds certainly to the legal point of view. It may not be as evident in other social contexts, however, and complete equivalence of these two statements will not be assumed here. By cross-classifying these modalities, we can categorize each act according to its feasibility and its conformance to a normative standard. There are twenty-four categories (six alethic modalities times four deontic modalities). The truth and normative values of each category show whether an act falling into it is likely to be performed. The consistency of the two values will show strain in the society on this topic. For instance, an act that is obligatory and necessary, or not permitted and impossible, will arouse little conflict. An act that is possible and not permitted, however, may lead to difficult situations; in the extreme, definitions of acts as necessary and not permitted are rare and likely to be unstable. Within a society, acts that are necessary and obligatory and their opposites will be supported by the institutional structure of the society. Acts that fall in the center of the continuum, which are permitted and possible, are left to individual decisions.

The assignment of an act to a particular category may change in a given society. Acts that are introduced into the society move from negation-that is, they are not done-to various stages of feasibility and may there encounter various relationships 
with norms. Of course, if it is initially at least normatively neutral, permitted or not obligatory, its chances of eventual acceptance are improved. If its acceptance has to overcome existing sanctions, if it is originally not permitted, the new act will with difficulty become part of the life of the society.

We can turn now to the logic of demographic change. During the stage of high birth rates and death rates, both birth- and death-controlling acts are nonexistent within the society. When measures that decrease the death rate attain higher truth values, longer life spans become feasible. These measures may sometimes run counter to social norms, but they are frequently neutral, and thus have varying degrees of difficulty in being accepted. What is important for their ultimate effect, however, is that the most effective of them move up frequently to obligations-for example, vaccinations, epidemic control, and sanitary measures-and with normative sanctions, these result in important consequences-for example, decreases in mortality rates. This is usually the case because the general act, to save lives, has high normative value; and even though specific measures may be against the prevailing norms, the normative system will tend to become consistent and to remove the obstacles to health improvement measures. Measures that do not run counter to norms will soon become obligatory, and norms may be changed to make other measures permissible.

With birth control, the situation is different. There is rarely a general norm to approve reduction of the birth rate in principle. Hence, there is little pressure to approve contraceptive measures. In fact, it is at least as likely that the prevailing norm is in favor of having many children rather than few. Thus, it becomes extremely unlikely that birth control will be felt as an obligation by the society, and the reduction in birth rate will trail behind that of mortality, leading to great population increases. Even in societies with low birth rates, contraception is an act falling in the categories of possible and permitted. In discussing the introduction of contraception in a society and its prospects, we have to consider first the framework of the society that leads to the removal of sanctions and introduction of knowledge-i.e., the move of contraception to the category of the possible and permitted. Within this category, however, action cannot be derived from logical necessities alone, but will depend on social and psychological conditions.

We can now discuss the introduction of birth control into Puerto Rico, noting the transition from different stages and identifying the present situation. ${ }^{4}$

\section{HIsToRY}

The first evidence of any interest in birth control occurred in the rg20's. Three separate attempts, one in each of the major cities of the island (Ponce, San Juan, and Mayaguez), were made between 1925 and 1932. Each of them foundered on opposi-

tThe following account is based primarily on Alvarado \& Tietze, Birth Control in Ptterto Rico, 12 Human Fertility i5 (1947); additional sources are cited elsewhere. 
tion of the Roman Catholic Church and public indifference. The first organized attempt at arousing interest in birth control can thus be summarized: there was no birth control (there was still not sufficient interest to inquire whether it was possible), and birth control was not permitted. The introduction of fertility control thus started under quite inauspicious circumstances.

The further dissemination of the technical possibility of contraception had to wait for the removal of the ethical sanction. This occurred as a result of government activity. The local federal relief agency, the Puerto Rico Emergency Relief Administration (PRERA), which was then a strong influence in many phases of Puerto Rican life, inaugurated a system of family-planning clinics in 1935, and at the height of the program, fifty-three clinics were established. This program, in contrast to its predecessors, was quite successful. This was not true in a clinical sense, since the women who attended the centers used the recommended methods only intermittently and inefficiently, and thus frequently became pregnant. ${ }^{5}$ They spread some information about the availability of birth control to a segment of the population, however, and government approval counteracted the negative sanctions. The situation thus started to move away from the moral sanction against birth control and also introduced the possibility that it could be attempted, although the possibility of an effective method may have been doubted.

Subsequent history bears out this analysis. The PRERA was terminated in 1936, and a month later, a new agency, the Puerto Rico Reconstruction Administration (PRRA) was created to take over its functions. But while opposition to the birthcontrol program was apparently ineffective in Puerto Rico, it was successful on the federal level in Washington, especially in a presidential election year. The maternal health program of the PRRA was, accordingly, terminated while it was still being organized. Within a short time, however, a private organization, the Maternal and Child Health Organization was founded and established twenty-three clinics.

In addition, the insular government continued its support of family planning. Governor Winship, a federal appointee, advocated measures supporting contraception, and the elected legislature authorized the teaching and practice of contraception and government support of it. ${ }^{6}$ Whether by design or accident, Governor Winship was absent from Puerto Rico at that time, and so the bill was signed by Acting Governor Menendez Ramos, a member of the insular government. Mr. Menendez Ramos not only signed the bill, but made a strong statement in its support at this occasion:?

Since most of the arguments in opposition have been moral and religious, I have given careful consideration to these. I have not convinced myself that the judicious use of contraception is in conflict with wholesome public morality in its broadest sense. On the other hand, those of us who have discussed the maldistribution of Puerto Rican lands

\footnotetext{
'See Beebe \& Belaval, Fertility and Contraception in Puerto Rico, I8 P.R.J. PuB. Health \& Trop. MED. 3 (rg42).

${ }^{\circ}$ Laws of Puerto Rico 1937, No. 136, at 294.

${ }^{7}$ Note, New Legislation, 2 J. Contraceptron II 8 (1937).
} 
and its growing absentee ownership must realize that these problems are growing more and more serious through our existing surplus population and its constant growth, particularly in recent years. The inevitable consequence is increasing unemployment, growing poverty and mounting misery.

These comments tied up the question of birth control with a dominant social problem of the time-land distribution-and affirmed fertility control as a Puerto Rican problem. Menendez Ramos was excommunicated from the Roman Catholic Church as a consequence of his actions, and he framed the excommunication document and displayed it proudly in his office. Events like these helped to neutralize the ethical sanctions propounded by the Roman Catholic Church.

The passage of the law was not in itself sufficient to remove all prohibitions on birth control, as the question arose whether it conflicted with federal legislationin particular, the Comstock law. ${ }^{8}$ When protests were made, the United States Attorney General ruled that the federal law did prevail and ordered proceedings against the persons conducting clinics. Six persons-two physicians and four officials of the Maternal and Infant Health Association-offered themselves as test cases, and United States District Judge Robert A. Cooper decided in favor of the defendants in January I939. ${ }^{\circ}$ In rendering his decision, he rejected the defense claim that the federal statute did not extend to Puerto Rico. He ruled, however, that "it is inconceivable that Congress could by legislation prevent a physician from prescribing properly to safe life and guard health. ..."10 This decision followed closely the reasoning of the Circuit Court of Appeals in United States v. One Package, which had held that the federal statute was not applicable to things that "might intelligently be employed by conscientious and competent physicians for the purpose of saving life or promoting the well-being of their patients."11 The court did, however, invalidate the sections of the Puerto Rican law that permitted prescription of contraceptives for purely economic and social reasons. In effect, this stricture was irrelevant, as malnutrition was an invariable concomitant of bad economic conditions.

This sequence of events resulted in a shift of the logical position of the institutional structure in Puerto Rico. As far as official sanctions applied, birth control was permissible and sufficient information was available to make it possible. In view of the claim that is sometimes made that the idea of birth control for Puerto Ricans is a solution advocated by mainland majority groups and implies discrimination against Puerto Ricans, ${ }^{12}$ it should be noted that the positive advocacy of contraception was clearly initiated and supported by Puerto Ricans, while federal officials were divided and at best neutral on the issue. The situation was such that

${ }^{8}$ Act of June 8,1872 , ch. 335, I7 Stat. 323. See 72 Stat. 962,18 U.S.C. $\$ 1461$ (1958).

- United States v. de Torres, D.P.R., Jan. I9, r939. For a report of this case, see The Decision in the Paeto Rico Case, 4 J. Contraception 81 (r939).

${ }^{10} \mathrm{Id}$. at 82 .

1186 F.2d 737, 739 (2d Cir. 1936).

${ }^{12}$ See, e.g., Frederic Werthan, The Circle of Guilt $118-20$ (1956). 
population control as a policy was advocated by local officials, while Washington kept to a more or less neutral course.

The period from I925 to 1939 witnessed the growing acceptability of contraception into Puerto Rican culture. We can infer that the original position was that there is no such thing; the early experiences showed that prohibition from a deontic point of view and impossibility from an alethic point of view were the dominant responses. In the few years from the establishment of PRERA to Judge Cooper's decision, both of these barriers to acceptance were overcome, at least as far as the official framework of the society was concerned. In contrast to similar measures that decrease mortality, the fertility-control pattern did not progress from here to being a positively accepted pattern of the culture, to becoming morally required and technically necessary. The further history of the maternal health clinics demonstrates this.

The clinics were established under the Department of Health after the court action had cleared the way. The history of the first seven years of their existence is summarized in the $1946-47$ Annual Report of the Commissioner of Health: ${ }^{13}$

The contraceptive service was established in the year 1939 under the name of Maternal Health Work. Originally this was purely a public health activity but eventually it was extended to cover the population control aspect of the problem. In July, I94I, a Consultant in Obstetrics was appointed in charge of the direction of this special service and was specifically instructed to intensify the work in the population control aspect. We worked toward this goal, trying to increase the number of new admissions to the service and to keep down the number of passive and closed cases. In the first year we were in charge of the services, we had 13,000 new admissions in our clinics and an increase of 4,000 cases over the previous years. The service continued until the war conditions hindered the progress of our work which was further curtailed in the year 1946 by a change in the policy of the Department of Health as to the Maternal Health Clinic program. The name was changed to Prematernal Health Clinics and it was specifically stated that these clinics would only have one determined purpose: that is, to improve the health of the women who, being married or living in consensual union would be exposed to becoming pregnant. Only in the presence of clear medical indications would contraceptive advice be given to these women. It was specifically decided that these clinics would have nothing to do with the problem of density of population. Needless to say this change in policy of the Department has caused a great drop in the course of our wotk.

This consciously neutral policy has since left the effectiveness of the clinics to the discretion of health department officials, and even more specifically to the directors of the local health units. Thus, while the clinics in general continued to operate modestly in this field in the I950's, one, which had a director actively interested in population control, invariably had high numbers of new admissions and active cases. The last few years have seen some renewed activity in this area augmented by the program of a voluntary organization, the Puerto Rican Family Planning Association. It cannot be said, however, that family planning has become a governmental policy or a positive part of the culture.

${ }^{13}$ Comaissioner of Health of Puerto Rico, 1946-1947 Annual Report i89 (1947). 
Atritudes

$\mathrm{U}_{\mathrm{p}}$ to this point, we have considered only the legal and formal framework of the society. The effect of these changes on the actual birth rate will depend, however, on the attitudes and information of individuals and within families. The changes in the institutional framework must be related to some degree with beliefs of what is right and what is true of the general population. Several studies have been undertaken on this issue. The following discussion is based on the most recent and intensive of these, which was conducted in $1954-55$ by the present authors. ${ }^{14}$ Changes can be seen by comparison with earlier studies conducted in I 948 by Paul Hatt, ${ }^{15}$ and $x 949$ by Emilio Cofresi. ${ }^{16}$

\section{A. Level of Information}

The level of information about contraception is a measure of the acceptance of the truth that family size can be limited. Here we find that the general level of knowledge of contraceptive methods corresponds to an acceptance of the possibility of birth control within the culture. Only five per cent or less of several samples of Puerto Rican women professed no knowledge of birth-control method, and the median number of methods known was over three, even for the rural respondents without formal education. The methods that are most known include the most modern and most effective, condom and female sterilization, with withdrawal and abstinence following. The methods that are known least, however, are those that principally involve action by the woman. This corresponds to the fact that men typically learn earlier about contraceptive methods than women. One-quarter of the women learned their first method only after the third pregnancy, while almost nine out of ten men had learned of at least one method before marriage. In so far as the woman's interest is crucial in effective birth control, this means that many women acquire the requisite knowledge too late, that they are less likely to learn about methods that they could use, and that husbands seem unwilling to impart the information to their wives. This situation puts contraception into the position of a possible action, but not of an action that is accepted as a natural part of a contemporary life, such as inoculations or provision of safe water.

Besides knowledge of existence of the methods, the knowledge of their availability is important. As the government program includes clinics that provide material and medical advice free of charge, the location of the nearest health center (of which these clinics are part) is known by nine out of ten people. The people who presumably would need the services of the health center most, however, rural residents and those with low education, are least familiar with it. Only eighty per cent

14 Reuben Hill, J. Mayone Stycos \& Kurt W. Back, The Faimls and Population Control; A Puerto Rican Experiment in Soctal Change (1959).

${ }^{15}$ Paul K. Hatt, Backgrounds of Human Fertility in Puerto Rico (1952).

${ }^{10}$ Eaillio Cofresi, Realidad Poblacional de Puerto Rico [Populational Reality of Puetito Rico] (195r). 
of the extreme group-rural, with no education-know the clinic's location. A similar condition holds about the knowledge of the birth-control service within the clinic. To a question, "If you or your wife wanted to get free birth control methods, where would you go?" only twenty-two per cent of rural residents without education answer "health center," while almost three-quarters of rural residents with more than an eighth-grade education do so. A similar relationship holds among urban respondents. It is, of course, likely that more people know how to obtain materials for pay. Just these persons who can least afford the price, however, do not know how to obtain them without payment. The passive policy of the clinics has made them quite well known among the generally well-informed, but little known among the people who have little active means to learn about new services. Use of the clinics is most highly concentrated in the rural, highly-educated group; more than one-sixth have used the services, while only one-tenth of the less-educated rural families have used them. There is little relation between education and use of the clinic among urban residents, and the proportion of use is generally lower. As incidence of contraception is higher among urban residents, it would seem that they use commercial outlets.

Comparing the figures of information about the clinics and actual experience with them, we can see that among the less-educated families, the clinic is mainly known when its services have actually been utilized. Among the better-educated groups, the knowledge is general and little dependent on actual use. A service, to be really effective, should be known widely among its potential users in order that it can be utilized when the need arises. In this case, however, we find that among the people who are most in need of free advice and materials, knowledge tends to be restricted to those who, for some reasons, have been able to obtain the services independently.

The information on birth control available to the general population seems to be a reflection of the official policy. The information is made available to persons who are interested, but no effort is made to see that it reaches a wide audience. Correspondingly, some vague information is distributed rather widely, but the population groups with few sources of general information have learned little. This knowledge does not readily reach the people who are most in need of it.

The same studies also give an indication of how far birth-control methods have become permissible. In general, there is a high acceptance of the idea of family limitation, which has even been increasing. The question, "Who has the right to use birth control?" was asked in the studies in 1948 and in 1954. The answer, "Nobody" was given by one-eighth of the women in I948, but by only one-half that many seven years later. The next restrictive answer, "Only people who need it for health reasons" was given by slightly more than a fifth in I948, but only by one-tenth in 1954. It should be noticed, however, that even at the earlier time, only a minority restricted the use of birth control as far as the court had set the legal limit. The majority, which had reached eighty-five per cent by 1954 , accepted it for economic reasons or set no limitations. 


\section{B. Influence of Religion}

The principal normative barrier to the use of birth control has been religious opposition, especially on the part of the Roman Catholic Church. In fact, this opposition is probably the main reason for the reluctance on the part of government officials to proceed with an active family-control program. We can inquire, therefore, what the influence of religion is on the issue. As Puerto Rico is eighty per cent Roman Catholic, the general high acceptance of birth control that we have just noted would argue against the strong influence of Roman Catholic doctrine. A more direct indication is afforded, however, by comparing the attitudes of Roman Catholics and non-Roman Catholics. In this comparison, Roman Catholics are a little less likely to take a restrictive position on the use. This slight reversal of expected form holds for most related questions. Thus, Roman Catholics are slightly more favorable toward a smaller family size; more of them have practiced birth control; and of those who have practiced birth control, they are less likely to have used Churchapproved methods, rhythm or abstinence. These differences are small, however, and cannot be taken as support for a claim that Roman Catholics are more likely to support a birth-control program than non-Roman Catholics. It does show, however, that the opposition of the Church is not reflected in the attitudes and practices of the rank-and-file Roman Catholics.

This discrepancy between the official position of the Roman Catholic Church and the attitudes of its communicants may be ascribable to a general lack of influence of the Church. In fact, a fairly high proportion of Puerto Rico's Roman Catholics may only be called such nominally - that is, they observe some of the rites of the Church, such as baptism and burial, but they have little contact otherwise. This is shown by the great number of consensual marriages, which in Puerto Rico is a stable alternative to formal marriage, and also by poor church attendance. Thus, it is known that only a small minority of Puerto Ricans attends services as much as once a month, with non-Roman Catholics more likely to attend church than Roman Catholics. Among both Roman Catholics and non-Roman Catholics alike, however, church-attenders are more likely to oppose birth control, prefer large family size, and show other traits unfavorable to contraception; but even among the frequent church-attenders, only a minority show strong opposition. For instance, only twenty per cent restrict admissibility of birth control to health reasons or deny it completely. There is, thus, among the church-attenders, both Protestant and Roman Catholic, a small hard core of persons who do really oppose birth control.

The fact that this opposed group is not necessarily Roman Catholic draws attention to the fact that the non-Roman Catholic group includes members of some sects that are also strongly opposed to contraception. These sects, which are small and compact organizations, are apparently able to control the attitudes and practices of their members better than can the dominant Roman Catholic Church, which is loosely organized on the island. This seems to be confirmed by the higher church 
attendance among non-Roman Catholics. We might infer that the low conformity of the Roman Catholics to the dogma represents the well-known phenomenon that a majority is less cohesive and less fervid in its beliefs than a minority. The same relationship or lack of it was found in Jamaica, however, where Roman Catholics form a minority. ${ }^{17}$ Here, followers of sects that in general were also opposed to contraception were distinguished from members of the larger Protestant churches, which in general accept birth control. Even under these conditions, Roman Catholics were, if anything, slightly more favorable to family planning than the two other groups.

Even frequent church attendance, however, does not necessarily guarantee compliance with the official beliefs. We have already seen that the proportion of churchattenders giving a pattern of answers negative to beliefs in family planning is very small. Indeed, if we turn to actual performance, we find that church attendance is related positively to use of birth control and to success with it. It is likely that for many persons, church attendance is mainly a means of social participation; it is highly related to other measures of social status, such as education and rent paid. This interpretation would help to account for an otherwise paradoxical experience in the course of conducting meetings designed to give knowledge of and instill motivation for using birth control. Of the women invited to meetings at which birth control was to be discussed, Roman Catholics were more likely to attend than non-Roman Catholics, and churchgoers more than nonchurchgoers. Thus, seventythree per cent of Roman Catholic frequent churchgoers came to the meetings, while only forty-eight per cent of non-Roman Catholic infrequent churchgoers attended.

In short, according to general opinion, birth control is a permissible, even a somewhat positively regarded action in Puerto Rico. Religious sanctions against it are largely ineffective, partly because of general low influence of the Roman Catholic Church. Even where people are aware of religious sanctions, they feel free to disagree, as the following quotes from interviews with lower-class respondents show:

"The Catholic religion says it's a sin to use birth control, but I think it's a greater sin if the children have nothing to eat."

"The Church forbids it but it is good to use birth control. The Church isn't going to support the children."

The normative position of the Puerto Ricans is somewhat more receptive to family planning than could be expected from official hesitation. It would seem likely that an active program would arouse little opposition from the general population, although it might mobilize some extreme groups.

\section{Individual Motivations}

The public policy of making birth control permissible and known to be possible is paralleled by the spread of knowledge and lack of opposition within the population. The general concern of public officials about the population problem is not publicized. Also, concern about population increase on a national level becomes

${ }^{17}$ See Stycos \& Back, Contraception and Catholicism in Jamaica, 5 Eugenscs Q. 256 (1958). 
something different if it is considered by individuals as a question of limiting the size of their own families. Thus, the actual effect of all the policies that we have discussed will depend on the individual motivations to keep the family size small.

There are some popular notions that assume that Puerto Ricans desire large families. In traditional agricultural societies, children have been an economic necessity, as labor force and as support of the parents in old age. The change of the society in recent years, however, has diminished the weight of this reasoning. The proportion of the population in agriculture has been decreasing, while aspirations for children have been raised. As practically all children go through at least eight grades of school and an increasing number proceed further, it becomes more important for parents to provide for them, and they have to be considered less as family workers. Moreover, improved economic conditions and social legislation make reliance on children less of a necessity in planning for old age. Of a group of lower-class men asked about their plans for old age, one-half had thought about this question. Among those who had thought about it, dependence on children ranked third, after social security and own savings, as a means of old-age support. In this circumstance, too, children are not an automatic economic asset any more, a change that fits in with the general decrease of importance of the extended family.

It has also been claimed that Latin-American men have an exaggerated concern with maleness, which manifests itself in part by claims for sexual prowess and desire for offspring, especially for many sons. This cultural trait, machismo, has been considered responsible for a preference for large families. While it is true that the term is used and macho is considered by many people to be a positive ideal, there has been much disagreement on the meaning of the term among the population, and other, nonsexual aspects have been found to be equally important. Even more striking, the tension to live up to this ideal has been found to be relatively small. In a sample of men, slightly less than one-half said they would like to have more sons as opposed to more girls or equal numbers of each. Detailed analysis of the group that gave the machismo answer to this and similar questions revealed that these men did not show in attitudes and actions within their own family a desire for many children. The consistent relationship among machismo and actual family-size ideals and related practices occurred only among the youngest and oldest age groups-that is, the groups that may have most anxiety about their own masculine performance. Expressions of machismo on the part of a minority are noticeable enough to catch the attention of observers.

The belief that machismo is a motivating ideal in others may have more effect than the corresponding attitudes themselves. On a variety of questions, men are more favorable to small families than their wives; however, women believe that their husbands are more interested in large families than they are themselves. This misperception is one of the factors that frustrates action in conformity with expressed wishes. 
The actual number of children desired, which has been obtained in several surveys, is uniformly between two and three. In a comparison of results of questions on ideal family size in fourteen countries, Puerto Rico showed the second lowest ideal, after West Germany. ${ }^{18}$ In fact, the answer "two or three" is so stereotyped to questions of this kind that it can be called a cultural norm, although a norm of attitude rather than of achievement. A more intensive investigation into the meaning of this ideal showed a great amount of ambivalent feeling about this issue. Many women who would agree with statements advocating small family size would also agree with their opposites. This inconsistency would be associated with inconsistency in behavior, such as late start of contraception and irregular use of birth-control methods. A further caution against accepting the family-size ideal at face value comes from the change in preferences over the course of marriage. From retrospective data, we learn that women were little likely to think of any definite family size at marriage; or if they did, they frequently had a higher ideal than later. It seems that the ideal is more or less a consequence of experience. Thus, it comes too late to be effective as a motivating force in achieving this ideal. Principally, it was those women who recalled having felt strongly about having a small family at an early time who also started using contraceptive methods. For the rest, the belief in small families has been mainly a vague feeling that was not important until great pressure from an actually large family was experienced.

III

\section{Practices}

\section{A. Surgical}

The lack of norms against family limitation and of norms either for or against large families, the freedom to use contraception without a strong effort to promote the use, the late acquisition of knowledge about contraception, and concern about family size among many women have brought about a peculiar phenomenon in Puerto Rico-namely, the high incidence of female sterilization. Sterilization for medical reasons has been legal in Puerto Rico; the actual start of its popularity has been traced to World War II. At that time, an Army physician treated a woman with a large family in extremely bad economic and physical conditions. He found sterilization indicated and performed it. Soon he had a number of other patients asking for sterilization. Gradually, his activity became widely known and he was denounced in a pastoral letter. This, however, served only to publicize the possibility of the operation. Other physicians and clinics were asked about it, and many have been willing to perform it. ${ }^{19}$

${ }^{18}$ Stoetzel, Les Attitudes et la Conjoncture Demographique: La Dimension Ideale de la Famille [Attitudes and the Demographic Situation: The Ideal Size of the Family], in VI WorLd Popuration Conference, 1954 Procendings I019 (E/Con.13/413) U.N. Pub. Sales No. x955.XIII.8).

${ }^{20}$ See Senior, Women Democracy and Bitth Control, 5 Humanss 221 (1952). 
Sterilization has fitted the conditions in Puerto Rico very well. The general level of knowledge of contraception is just sufficient that the existence of an operation that can prevent further child-bearing is well known. It can be talked about much more easily than other methods, and it has been impressive to research workers to find out how well people know which of their friends and neighbors are sterilized. If the general policy has led to the minimum knowledge in the society that contraception is possible, this knowledge has initially been that sterilization is possible. Similarly, the normative conditions are favorable to this method. With little in the way of effective norms existing in favor or in opposition to family limitation, consistent use of any method is hard to support. If the need for further restriction of family size is felt, however, a method that is effective once and for all is easily resorted to.

Ironically, it is, in part, the efforts on the part of the strongest moral opponent of birth control, the Roman Catholic Church, that seem to promote the popularity of sterilization. Pastoral letters denouncing its use were instrumental in spreading the knowledge about it. Further, some case histories indicate that sterilization is resorted to by practicing Roman Catholics to avoid the embarrassment of confessing the same sin frequently, which is necessary when other contraceptive methods are resorted to. Sterilization solves the ethical as well as the practical problem once and for all. It is, therefore, appropriate under conditions where conflicting pressures have vitiated all effective social influences on this issue and its resolution is left to personal decision according to immediate circumstances.

The extent of increase in popularity of sterilization has been impressive. In the years $1944-\mathrm{rg} 5^{\circ}$, the number of sterilizations in district hospitals almost doubled; and in 1950, postpartum sterilizations were performed on eighteen per cent of all deliveries in district hospitals, where about forty per cent of all deliveries took place. Since then, hospitals have not released the data, partially because of the unfavorable publicity connected with it. For instance, accreditation of a hospital by the American Hospital Association depends, in part, on keeping sterilization below a certain percentage of all operations. But other evidence shows the increasing importance of this fertility-control technique. Hatt's survey in 1947 estimated that about six per cent of the women were sterilized, but there are reasons to believe that this was an underestimation. Cofresi, in I949, estimated the rate of sterilization to be from 3,000 to 4,000 annually. Exact data on sterilization from hospitals have not been available since I950. Our surveys, taken $1953-54$, led to the conclusion that onesixth of all women of child-bearing age were sterilized.

The availability of the operation is quite apparent. A major hospital shows on its reception desk a price list for obstetric service, including sterilization as a standard addition, just like a private room or Caesarean section. For women who cannot afford the cost-and most public hospitals charge only twenty-five to thirty dollarsa blood donation of two pints is accepted in payment. This system has become one of the main sources of supply for the blood bank. As the necessity for operations 
in public hospitals has to be certified by a public official, this certification has become an important source of patronage for the mayor.

The effect of this widespread practice on fertility is not as drastic as could be supposed. This happens because the sterilization seems to be performed mainly when strong pressure is felt. Although there is some reason to believe that sterilization tends to occur earlier, in I954, the majority of the sterilized women underwent the operation some time after their fourth pregnancy. The emphasis on sterilization also has some unexpected side effects. Unless there are strong medical indications, many physicians are naturally reluctant to perform the operation very early in a woman's reproductive life, as there is a possibility that she may regret the decision. This motivates women who are eager to have the operation performed to reach the required number quickly and thus the practice becomes detrimental to the spacing of children.

It is likely, therefore, that a program of population control will not depend primarily on sterilization, which can be viewed better as an emergency measure from the point of view both of the person and of the society. Over the long run, family planning will be accomplished through nonsurgical methods, partly because the attractiveness of planning to the individual is more in terms of spacing than in terms of absolute size. We shall turn now to the extent of use of these methods, its relation to the structure of Puerto Rican society, and its outlook for the future.

\section{B. Nonsurgical}

The proportion of women who have ever used a nonsurgical method has been found to be close to fifty per cent. Earlier studies had found somewhat contradictory rates; while Cofresi had found one-third of the women with previous contraceptive experience, Hatt found the incidence so low that it was impossible to analyze it further. The present figure is based on a rather close agreement of two separate surveys. While it is likely that some increase has actually occurred, some of the difference may be owing to the greater acceptability of birth control and greater willingness to admit it, and also to the improvement of interviewing techniques. Actual increase is confirmed, however, even in our surveys, as women over fifty years of age had had less experience with birth control than younger ones.

Besides age, education and residence are important factors in the use of contraception. Women living in urban areas and with higher education are more likely to have practiced birth control. The manner in which these factors affect planning can be seen from the attitudes that are related to both. Attitudes of this kindsuch as belief in planning in general, strength of concern in small family size, especially if it occurred early in marriage, belief in one's own effort rather than fate, and similar nontraditional values-are all related to the socioeconomic factors and are also associated with the practice of birth control. Use of contraception is, therefore, aided by institutions that promote cultural change, such as schools, industries, 
and cities. Within this permissive framework, it is the individual acceptance of planning and self-responsibility that will encourage the use of birth control.

Use of birth control itself is only a small part of the story. In fact, the average difference in number of pregnancies between users and nonusers is only 7 pregnancies. The use of birth-control methods does not necessarily guarantee effective family-size planning. If nonsurgical methods are employed, continued and regular use is the real condition for any reduction in birth rates.

It is in just this respect that the use of birth control is most deficient. Fertility histories show, again and again, interruptions or irregular use that actually vitiate any usefulness of birth control. And, the main reason for the interruptions is a consequence of irregular use: one-third of the women give lack of confidence or actual failure as the reasons for their discontinuance of birth control. Further important reasons cited are decrease of sexual pleasure or fear of injury by the method. Few women stop because of social pressure or guilt, religious or otherwise.

Within this context, we can see the consequence of the position of birth control within the logical scheme developed earlier. Although there is no assertion of impossibility or immorality of birth control, contraception has no institutional supports. It is not considered as an act that is natural and logically necessary, nor an act that is morally prescribed. Thus, there is no particular support for people who are using contraception. To persist in it regularly, some reinforcement is needed. This reinforcement may be some strong belief in planning, a belief in small family size, or a situation within the family that is conducive to joint action.

Two typologies of families could be constructed that show the kinds of situation that are conducive to regular use. We can classify families according to their position in the social order, which makes them more or less likely to accept new ideas. The factors used for this classification are residence, education, and type of marital union. Women in urban areas, with higher education, and living in legal marriage, are most likely to continue using contraception if they have started to do so. The other classification concerns relations within the family. The factors are the wife's working outside the home (as an expression of autonomy of behavior); small number of prohibitions on the wife's activities, such as wearing makeup or dancing with other men; and low dominance by the husband, as expressed by answers to questions of who does the shopping, who settles arguments, and who controls sex relations. The less restrictively the family is organized, the higher the chance that family planning will be consistent and effective.

As can be expected, these two types, the highly urbanized and the nonrestrictive family, are likely to occur together, and so the effect is frequently cumulative. The latter set of conditions, however, the family situation, seems to provide the added reinforcement needed for consistency of behavior in the absence of institutional support. Of all single indices gained from interviews, the most valuable in this connection was the amount of discussion between husband and wife of relevant issues. This was related to background, to significant values, and to the use of and the 
consistency in the use of contraception. It can be called the hub variable in a scheme of family planning in Puerto Rico.

The family, then, is the institution in which the consistent use of contraception is anchored. Changes within the general family situation are quite slow and difficult to influence directly. The future of family planning lies, however, in reliance on changes of this kind, unless some other institutional support, through policies or educational efforts, is given. Before indicating the possible paths that those changes could take, let us consider an experimental study that may be a microscosmic representation of future developments.

In this effort, matched groups of families were exposed to six kinds of experimental programs. One of the programs was a series of meetings discussing the values of small families and giving medical information on birth control. Another program consisted of a series of meetings devoted to a discussion of family organization and the need for communication between husband and wife. The third program consisted of a series of meetings dealing with both of the topics. Three other programs dealt with the same subject matter, but instead of conducting meetings, the information was put into short pamphlets and distributed to equivalent groups. The participants were interviewed three times-before the program, six weeks afterwards, and one year later. A control group was interviewed at the same three times, but not exposed to any program.

The women selected for the experiment were chosen for the need for birth control and matched according to their predisposition for it, as revealed in interviews. One group had the most favorable disposition on all counts-attitudes, information, and family organization; the other three groups were unfavorable in one of the three respects.

The outcome of these experimental programs show both the ease of initiating the use of birth control and the difficulty in maintaining it. The group that was most predisposed originally responded to the slightest stimulation. The pamphlets were very effective in starting the use of birth control, more than the group meetings; and even the control condition had a noticeable effect, presumably through the interview by itself. Among the groups that were somewhat negatively inclined in some respect, the programs dealing with that topic were effective in starting the use of contraception. On the other hand, continued use was more difficult to achieve. Over the long run, meetings, especially those that emphasized values and information proved most influential. Although the use started in these groups frequently only after the second interview, it proved lasting after one year, and these programs had the strongest effect on actual fertility.

The Future

The two distinct types of effect of educational programs point to two ways in which family planning can progress. Simple arousal of saliency of the issue, the 
reminder-type programs, can produce the decision to use birth control. As birth control is possible and permissible, little incentive is needed to try it a few times. On the other hand, strong reinforcement and commitment is needed for continued use; and only a quite intensive program can provide them.

Future programs can capitalize on one or the other method. Reliance on temporary saliency of the issue makes methods that have to be employed only once or that are extremely easy to administer very attractive. This is attested to by the continuing popularity of female sterilization. The Puerto Rico Family Planning Association has also started a program of male sterilization, of smaller proportion. The favorable conditions for easy methods has given some acceptance to the use of contraceptive pills. Although the distribution is still in the experimental stage, recent reports show successful use. In a two-year trial, 560 women had only twenty-four unplanned pregnancies during their use of the pill. Two hundred and forty-seven women withdrew from the program, however, and this is an ominous reminder of the experience of the clinic. ${ }^{20}$

It appears also that the social situation is gradually becoming more favorable to reinforcing the use of birth control. Private organizations, especially the Puerto Rico Family Planning Association, have been more active. The government clinics, under the guidance of a more sympathetic Secretary of Health, seem to be embarking on a more positive program. The combined influence of all these factors is seen in the declining birth rate. It is 32.1 per thousand in 1959, as compared to 37.5 in 1949-1953.

Puerto Rico provides an example of the difficulty of applying a criterion of acceptability of a birth-control program. ${ }^{21}$ The forces that affect the constitutional framework of the society, preventing birth control from becoming a positive policy and sometimes even obstructing a permissive policy, are not effective among the majority of the population. The effect of this ambiguous political and legal position, however, makes the popular response to a felt need vague and ineffective. Thus, programs favoring family limitation become possible innovations, like other technical advances, although they may be hindered by lethargy and opposed by some entrenched groups. Given freedom of choice of the people concerned, however, effective population-limitation programs, like other modernization programs, can succeed. In Puerto Rico's case, we are witnessing a slow, but steady, congruence of all the influences making family planning an accepted part of the society.

${ }^{20}$ Winfield Best \& Frederick S. Jaffe (Eds.), Simple Methods of Contraception 21 (1958).

21 Cf. Davis \& Blake, Birth Control and Public Policy, 29 Commentary 115 (I960). 